Article

\title{
Effect of Surfactant Polyvinyl Pyrrolidone on the Properties of Microporous Carbon Nanospheres Reinforced Magnesium Matrix Composites
}

\author{
Lin Jin ${ }^{1} \mathbb{D}$, Yong-Zhen Yang ${ }^{2, *}$, Jian-Feng Fan ${ }^{2}$ and Bing-She $\mathrm{Xu}^{2, *}$ \\ 1 College of Mechanical and Vehicle Engineering, Taiyuan University of Technology, Taiyuan 030024, China; \\ jinlin@tyut.edu.cn \\ 2 Key Laboratory of Interface Science and Engineering in Advanced Materials (Ministry of Education), \\ Taiyuan University of Technology, Taiyuan 030024, China; fanjianfeng@tyut.edu.cn \\ * Correspondence: yangyongzhen@tyut.edu.cn (Y.-Z.Y.); xubs@tyut.edu.cn (B.-S.X.); \\ Tel.: +86-0351-601-0311 (Y.-Z.Y.); +86-0351-601-0311 (B.-S.X.)
}

Received: 15 September 2020; Accepted: 16 November 2020; Published: 17 November 2020

check for updates

\begin{abstract}
Microporous carbon nanospheres (PCNS)-reinforced magnesium (Mg) composites were prepared using polyvinyl pyrrolidone (PVP) as surfactant and PCNS as reinforcement. The influence of PVP treatment and the effectiveness of PCNS on the mechanical properties of Mg-based composites were investigated. The results show that the PCNS can enhance the properties of the Mg matrix. Moreover, the PVP can effectively improve the dispersion of PCNS in the Mg matrix but had a negative influence on the tensile properties of composites. The $\mathrm{MgO}$ films with high tensile strength were produced between matrix and reinforcement after removing PVP, which effectively promotes the interface compatibility and improves the properties of the composite. The tensile yield strength and specific strength of PCNS-reinforced Mg matrix composite exhibited $177 \mathrm{MPa}$ and $102.4 \times 103 \mathrm{~N} \cdot \mathrm{m} / \mathrm{kg}$, respectively, which were $77 \%$ and $78 \%$ higher than those of the $\mathrm{Mg}$ matrix.
\end{abstract}

Keywords: magnesium matrix composites; microporous carbon nanospheres; polyvinyl pyrrolidone; interfacial bonds; mechanical properties

\section{Introduction}

As one of the lightest structural metals, magnesium $(\mathrm{Mg})$ has many advantages of high specific strength, good damping, machinability and recyclability. Nanocarbon materials have been added into $\mathrm{Mg}$ matrix composite as reinforcements, which not only can maintain the outstanding properties of the Mg matrix but also overcome the intrinsic demerits of the $\mathrm{Mg}$ [1-3]. Microporous carbon nanospheres (PCNS), which are zero-dimensional structure and isotropy carbon nanomaterials, have a huge prospects for application in batteries, biomedicine, composite materials, energy storage and many other fields because of their good characteristics, such as low-density, good acid-base stability, low thermal expansion rate, nontoxic and potential in energy dissipation [4-6]. Meanwhile, PCNS is also proposed as an ideal reinforcement material for metal matrix composites. However, PCNS have poor dispersibility and compatibility in metal matrixes because of their high surface energy and specific surface area, limiting the proportion of nanocarbon reinforcement added in the $\mathrm{Mg}$ matrix directly and then impeding the improvement of composite properties.

In many preparation processes of metal composites, surface functionalization [7] could be used to functionalize the reinforcing phase, which can improve the dispersibility of the reinforcing phase and the compatibility of two phases effectively. At present, researchers have tried to use surfactants, such as cetyl trimethyl ammonium bromide (CTAB) [8], polyvinyl alcohol (PVA) [9], sodium dodecyl benzene 
sulfonate (SDBS) [10] and polyvinyl pyrrolidone (PVP) [11] to modify nanocarbon reinforcement. After this, the reinforcing phase is mixed with the Mg matrix and obtains the composites with homogeneously dispersed nanocarbon in the metal matrix. Finally, the properties of composites are improved. However, in fact, there are few surfactants to be used in the active Mg matrix. The selection of surfactant and formulation of the process should be based on the premise of avoiding Mg oxidation. Research has found that surfactant PVP can be dissolved in ethanol and improve the dispersibility of nanocarbon materials effectively [12-14] while make $\mathrm{Mg}$ isolate from air oxidizing. Our previous research showed that PCNS was surface-functionalized by dissolving PVP in ethanol, and the uniform PCNS with pristine structure could be obtained [15], suggesting that the PVP contributes to the preparation of nanocarbon-reinforced $\mathrm{Mg}$ composites with homogeneous nanocarbon dispersibility.

PVP is an organic reagent and plays a positive role in the dispersion of the reinforcing phase. However, it may have a negative effect on the mechanical properties of bulk Mg composites. To investigate the influence of PVP and the effectiveness of PCNS on Mg-based composite properties, PCNS was used as the reinforcing phase in this work. After ultrasonic pretreatment with dispersant PVP, PCNS was mixed with Mg powders. Then the composite powders were prepared by the PVP removal process. After this, these powders were fabricated into bulk Mg matrix composites by spark plasma sintered (SPS) and hot-press methods. The characterization and analysis of the samples were carried out to investigate the role of PVP in the composites preparation process and the influence of removing PVP on the properties of composites. Moreover, the possibility of PCNS for enhancing $\mathrm{Mg}$ was studied. The purpose of this work is to improve the preparation technology of homogeneously dispersed PCNS-reinforced Mg matrix composites and provide a reference for zero-dimensional carbon structure as reinforcement applied in the Mg matrix composites.

\section{Materials and Methods}

\subsection{Materials}

PCNS were selected as nanocarbon reinforcements, which were prepared by hydrothermal method at the laboratory [16]. The field emission scanning electron microscopy (FESEM) image of PCNS is shown in Figure 1. Mg powders (purity, 99\%) with $75 \mu \mathrm{m}$ of particle size and PVP with $30 \mathrm{~K}$ were supplied by Tianjin Guanfu fine chemical research institute Co., Ltd., Tianjin, China.
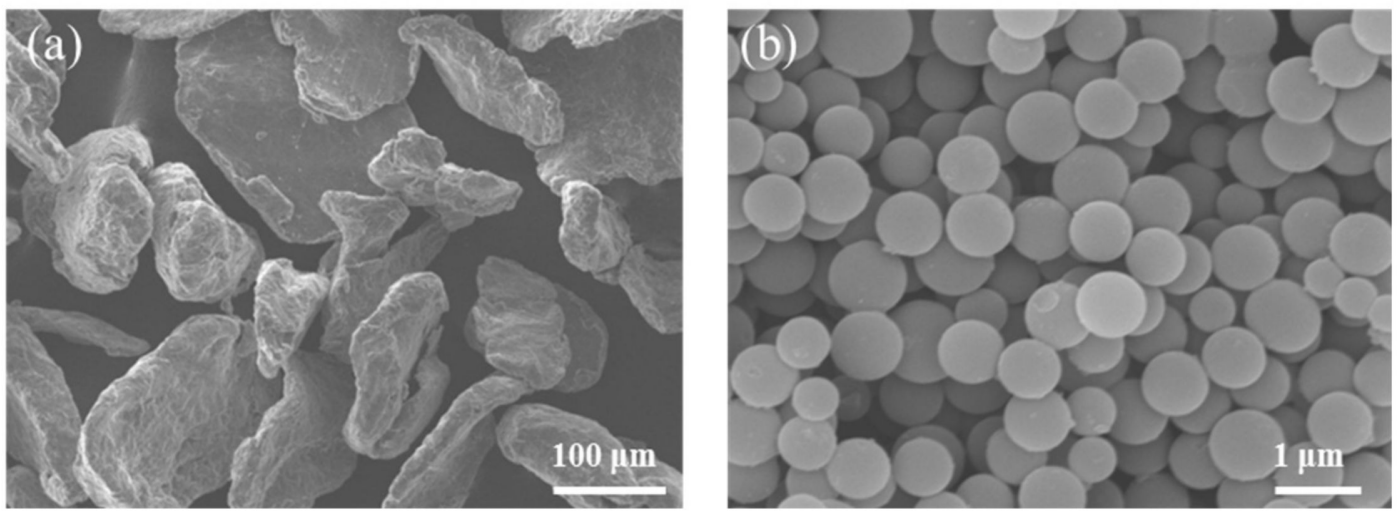

Figure 1. Field emission scanning electron microscopy (FESEM) image of (a) the Mg powders and (b) the microporous carbon nanospheres (PCNS).

\subsection{Material Processing}

The preparation process of carbon-reinforced Mg composites used is illustrated in Figure 2. 


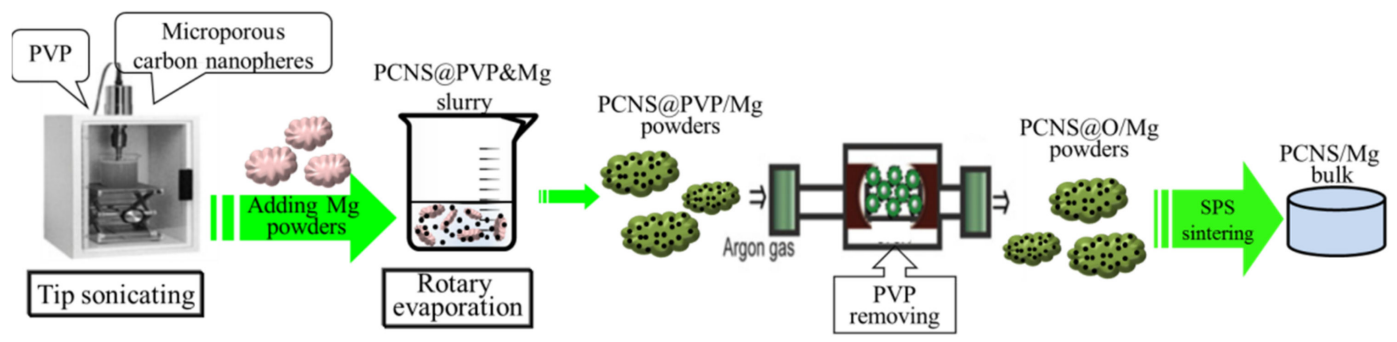

Figure 2. Preparation procedures for PCNS-reinforced Mg composite powders.

\subsubsection{Preparation of Carbon-Reinforced Mg Composite Powders without PVP Pretreatment}

A certain mass percentage of PCNS was mixed into $50 \mathrm{~mL}$ of ethanol. The ethanol slurry with the mixture was obtained by tip ultrasonic dispersion for $1 \mathrm{~h}$. The mass percentage of the Mg powders corresponding to PCNS was put into ethanol slurry. Then, the PCNS-reinforced Mg composite powders, named PCNS/Mg, were obtained by removing ethanol with a rotary evaporator and vacuum drying.

\subsubsection{Preparation of Carbon-Reinforced Mg Composite Powders with PVP Pretreatment}

PVP was dissolved in ethanol with a concentration of $10 \mathrm{~g} / \mathrm{L}$. A certain mass percentage of PCNS was added into the PVP solution of $50 \mathrm{~mL}$, and their black slurry PCNS@PVP was obtained by tip sonicating for $1 \mathrm{~h}$ to functionalize the PCNS. Then, a mass percentage of the Mg powders corresponding to the reinforcing phase was put into PCNS@PVP slurry. Afterward, the rotary evaporator and vacuum drying were carried out to remove ethanol, for obtaining the primed $\mathrm{Mg}$ composite powders with PCNS uniformly dispersion, denoted as PCNS@PVP/Mg.

\subsubsection{PVP Removal Treatment}

The PCNS@PVP/Mg primed composite powders were processed under flowing argon gas at $480{ }^{\circ} \mathrm{C}$ for $2 \mathrm{~h}$ to remove PVP, and thus the final PCNS@O/Mg composite powders were obtained.

\subsubsection{Processing of Carbon-Reinforced Mg Composite Bulks}

Thirty-five grams of the composite powders was molded into a graphite mold of $\Phi 40 \mathrm{~mm} \times$ $15 \mathrm{~mm}$ by SPS at $50 \mathrm{kN}$ and $560^{\circ} \mathrm{C}$. Then composite bulk was hot-pressed into a bar with $\Phi 10 \mathrm{~mm}$. The samples for the tensile tests were prepared by wire-electrode cutting.

The composite bulks, which are named as xPCNS/Mg for PCNS mass percentage, were fabricated with PCNS/Mg composite powders by SPS and hot-pressing. The samples with a different mass percentage of PCNS are shown in Table 1.

Table 1. Tags of samples without polyvinyl pyrrolidone (PVP) pretreatment by regular methods.

\begin{tabular}{cc}
\hline Mass Percentage of PCNS (wt.\%) & Bulk Sample \\
\hline 0.5 & $0.5 \mathrm{PCNS} / \mathrm{Mg}$ \\
1 & $1 \mathrm{PCNS} / \mathrm{Mg}$ \\
\hline
\end{tabular}

The composite bulks named as xPCNS@PVP/Mg were molded with PCNS@PVP/Mg composite powders by SPS and hot-pressing. In the meanwhile, the composite bulks tagged as xPCNS@O/Mg were fabricated by PVP removal treatment and molding. The samples with a different mass percentage of PCNS are shown in Table 2. 
Table 2. Tags of PCNS/Mg composite samples with PVP pretreatment.

\begin{tabular}{ccc}
\hline Mass Percentage of PCNS (wt.\%) & Bulk Sample & Bulk Sample of Removing PVP \\
\hline 0.5 & 0.5 PCNS@PVP/Mg & 0.5 PCNS@O/Mg \\
1 & 1 PCNS@PVP/Mg & 1 PCNS@O/Mg \\
2 & 2 PCNS@PVP/Mg & 2 PCNS@O/Mg \\
4 & 4 PCNS@PVP/Mg & 4 PCNS@O/Mg \\
\hline
\end{tabular}

\subsection{Characterization}

The dispersion of reinforcement and fracture morphology of composite samples were examined by field emission scanning electron microscopy (FESEM, Japan Electronics Co. LTD, Tokyo, Japan). Phase analyses of composite powders were performed by X-ray diffraction (XRD, Rigaku Co. LTD, Tokyo, Japan), thermogravimetry-differential thermal gravity(TG-DTG, Beijing Optical instrument Factory, Beijing, China) and Fourier-transform infrared (FT-IR, Bio-Rad Laboratories, Hercules, CA, USA). The microstructures of samples were examined by optical micrographs. The interface structures of composites were investigated by energy-dispersive X-ray spectroscopy (EDS, Japan Electronics Co. LTD, Tokyo, Japan) and high-resolution transmission electron microscopy (HRTEM, Japan Electronics Co. LTD, Tokyo, Japan). The tensile test was carried out on a tension machine at room temperature.

\section{Results and Discussion}

\subsection{Influence of PVP on Reinforcement Dispersion}

Figure 3 shows the FESEM images of PCNS/Mg and PCNS@PVP/Mg composite powder samples. It can be observed in Figure $3 a$ that the PCNS reinforcement were scattered on the cracks and surface of the Mg particles with obvious agglomeration. The functionalized PCNS by PVP pretreatment were homogeneously absorbed on the surfaces of the $\mathrm{Mg}$ particles without evident agglomeration of reinforcement in the cracks of composites, as shown in Figure $3 \mathrm{~b}$. The above results prove that the functionalization of carbon reinforcement by PVP could effectively improve the dispersibility of the reinforcing phases, which were absorbed on the surface of the $\mathrm{Mg}$ particles. This may have been due to the action of dispersant PVP, which increased the repulsion interactions of the electrical double layer, hydration retia and steric hindrance [17] and decreased Van der Waals attraction among reinforcement. When the ethanol evaporated, diffuse PCNS were coated on the surface of the Mg particles by PVP film.
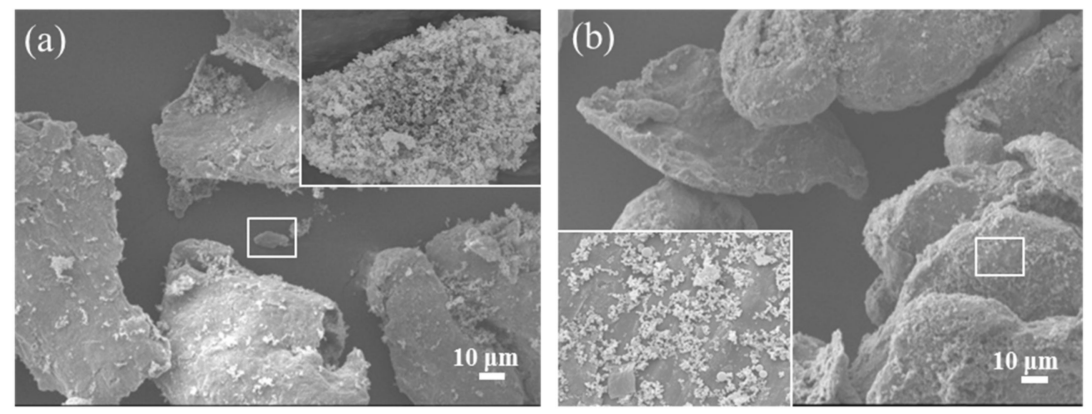

Figure 3. FESEM images of the samples by different decentralized processing: (a) PCNS/Mg, (b) PCNS@PVP/Mg.

\subsection{Influence of PVP on Composite Powders}

The XRD patterns of PCNS@PVP/Mg and PCNS@O/Mg composite powders were examined to analyze the transformation of composite powders in PVP removal. Figure 4a illustrates the characteristic peaks at around $32.16^{\circ}, 34.39^{\circ}, 36.59^{\circ}, 47.80^{\circ}, 57.36^{\circ}, 63.05^{\circ}, 68.65^{\circ}$ and $69.99^{\circ}$ corresponding to $(100)$, (002), (101), (102), (110), (103), (112) and (210) of the Mg and a broad diffraction peak related to PCNS at around $22.1^{\circ}$ corresponding to (002) [18]. As shown in Figure $4 b$, the low-intensity diffraction peak 
at around $43.0^{\circ}$ was the characteristic peak of the $\mathrm{MgO}$ except for characteristic peaks of the $\mathrm{Mg}$ and PCNS in PCNS@O/Mg composites. This indicates that a small amount of the $\mathrm{MgO}$ was produced by oxidation of the Mg particles in PVP removal. It is worth noticing that the diffraction peak of PCNS in Figure $4 \mathrm{~b}$ is sharper than Figure $4 \mathrm{a}$. That can be concluded the PCNS of primed composite powders is graphitizing without destroying its structure in PVP removal [19]. The influence of PVP removal on properties of composite bulks should be tested by in latter.

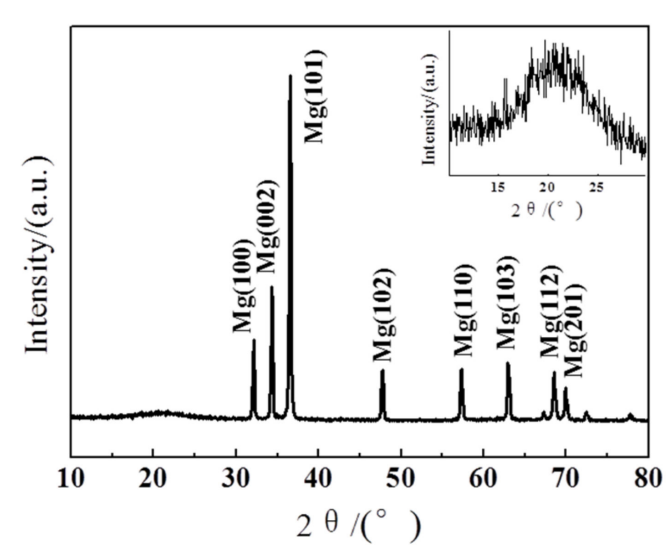

(a)

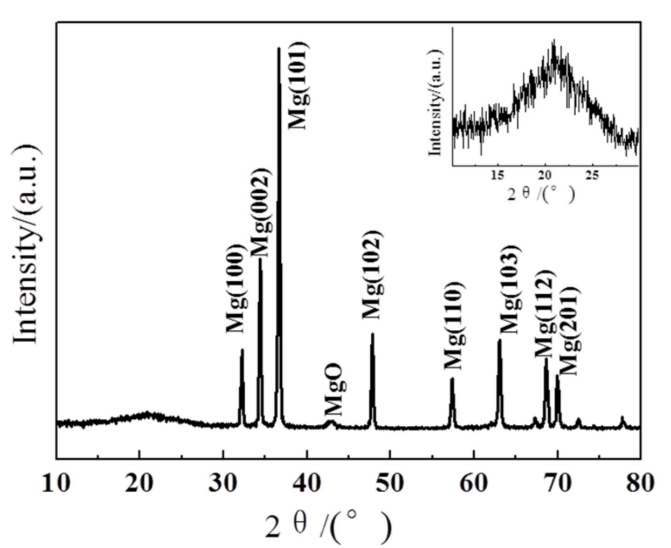

(b)

Figure 4. X-ray diffraction (XRD) pattern of PCNS-reinforced Mg composite powders before (a) and after (b) PVP removal.

In order to further study the transformation of composite powders after PVP removal. TG-DTG analysis was performed in an argon atmosphere in the temperature range from 30 to $500{ }^{\circ} \mathrm{C}$ at a heating rate of $5^{\circ} \mathrm{C} / \mathrm{min}$. From the TG curves in Figure 5, it can be seen that the weight loss occurred from 290 to $470{ }^{\circ} \mathrm{C}$, and the loss ratio was $2 \mathrm{wt} . \%$. With the temperature of heating was below the melting point of the $\mathrm{Mg}$, it was considered that the weightless is caused by the oxidization of PVP. As observed in the DTG curve, the weight loss peak at $330{ }^{\circ} \mathrm{C}$ was attributed to the hydroxides on the surface of the $\mathrm{Mg}$ particles on composite powders [20]. The loss weight peak at $420^{\circ} \mathrm{C}$ was due to almost complete oxidation of PVP. It was proved that PVP removal could eliminate PVP and hydroxides on the surface of the $\mathrm{Mg}$ particles and produce a small amount of $\mathrm{MgO}$ at the same time.

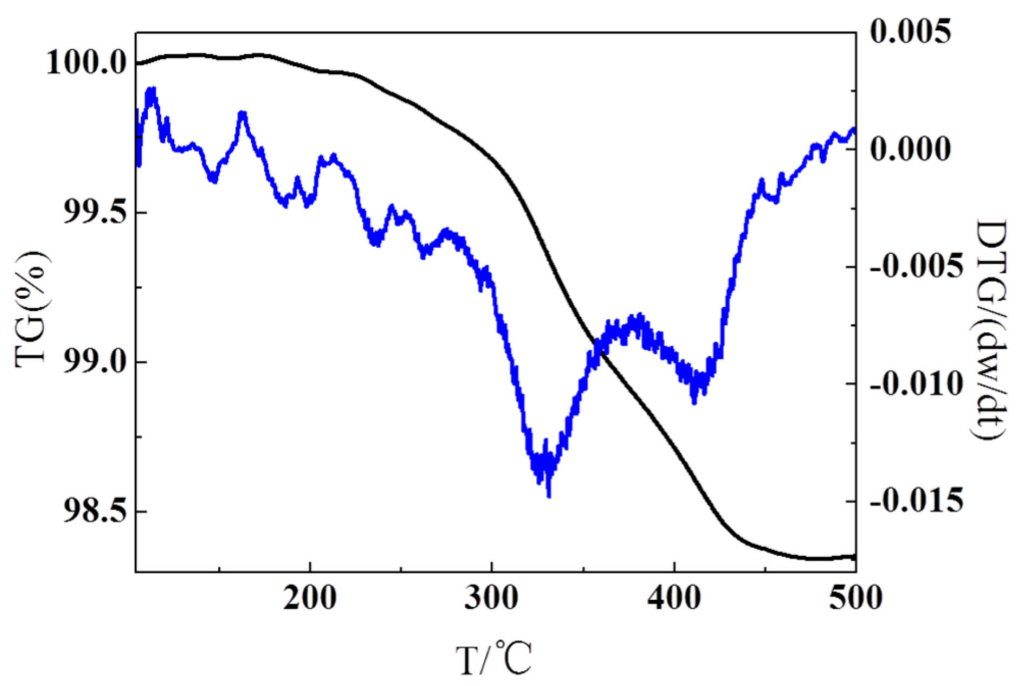

Figure 5. TG-DTG analysis of PCNS@PVP/Mg powder samples. 


\subsection{Influence of PVP on Optical Micrographs of Bulk Composites}

Figure 6 shows the optical micrographs of xPCNS@PVP/Mg composite bulks by SPS and hot-pressing. The left and right images are the microstructure of composites with vertical and parallel to the extruded direction, respectively. Moreover, the inset is the grain size distribution of the composites. The $\mathrm{d}_{\text {average }}$ represents the grain average size, which is the average width in the parallel section of the sample in order to reflect the microstructure of composite bulk objectively. As shown in Figure 6, the average grain sizes of the sample decreased with an increasing mass percentage of PCNS from 0.5 to $2 \mathrm{wt} . \%$, the distribution range of grains decreased concurrently. The average grain size of 2PCNS@PVP/Mg was minimum with about $10.27 \mu \mathrm{m}$, and the size distribution range was the narrowest, from 3.21 to $43.57 \mu \mathrm{m}$, which showed the grains of 2PCNS@PVP/Mg were more small and uniform than those of other xPCNS@PVP/Mg samples. When the content of PCNS was added up to $4 \mathrm{wt} . \%$, the average grain sizes and grain boundary width of samples are increased, with many clusters of PCNS observed at the Mg grains boundary obviously. The formation of broad grain boundary and voids may have been due to excessive PCNS can agglomerate so that they were not closely bound to the $\mathrm{Mg}$ matrix, resulting in corrosion and peeling in producing metallographic samples.

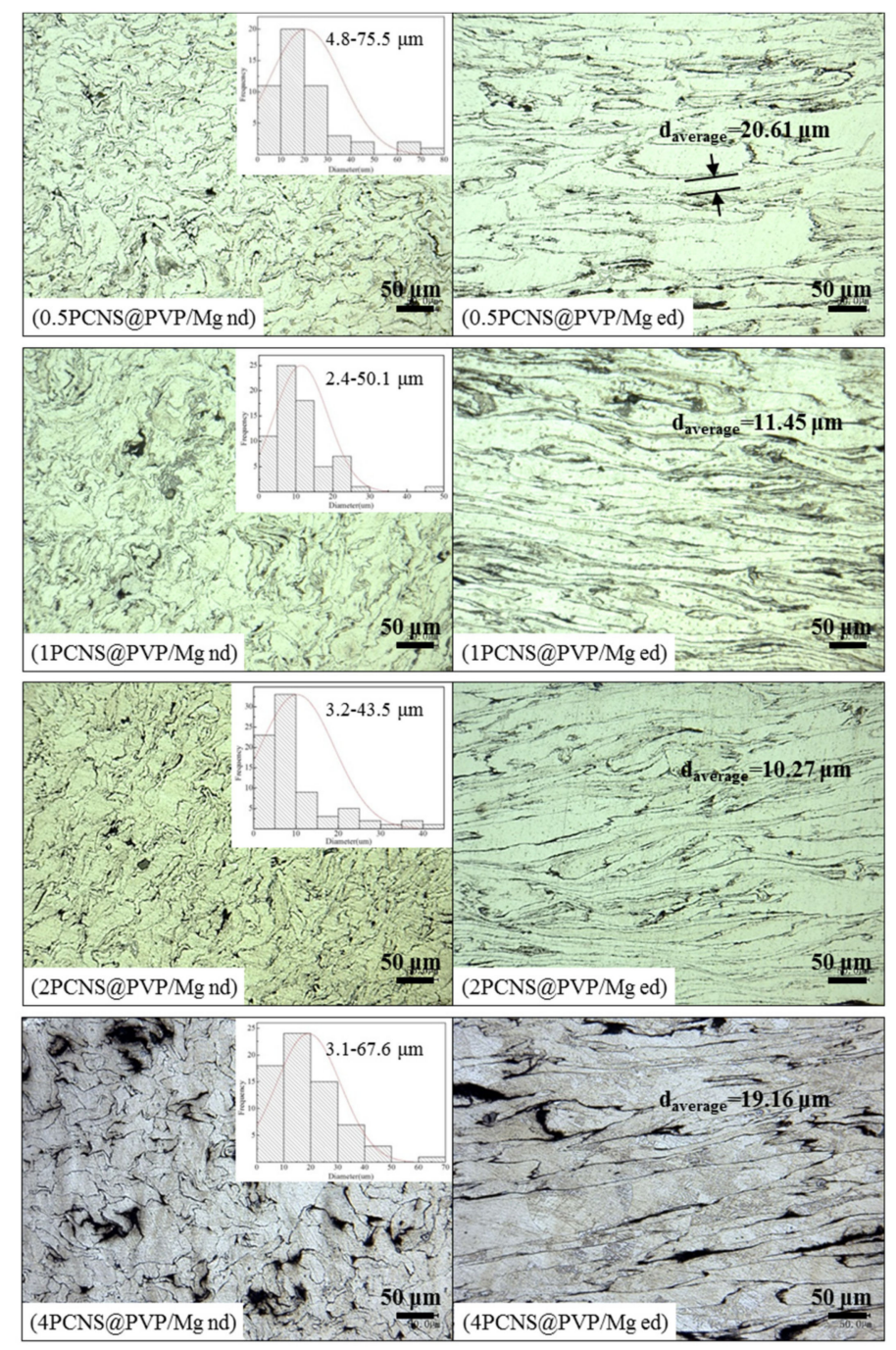

Figure 6. Optical micrographs of xPCNS@PVP/Mg bulk composites with the content of PCNS were 0.5, 1,2 and $4 \mathrm{wt} . \%$. The left and right images are the microstructure of composites with vertical (nd) and parallel (ed) to the extruded direction. 
The samples of xPCNS@O/Mg showed the same trend as the xPCNS@PVP/Mg samples. As shown in Figure 7, the average grain sizes and size distribution range of xPCNS@O/Mg first decreased and then increased with increasing content of PCNS from 0.5 to $4 \mathrm{wt} \%$. The average grain size of 2 PCNS@O/Mg was minimum with about $12.41 \mu \mathrm{m}$, and the size distribution range was narrowest, from 3.34 to $30.20 \mu \mathrm{m}$, which proved that adding uniformly dispersed PCNS played a positive role in grain refinement and homogenization of composites. However, the grain sizes of xPCNS@O/Mg samples were larger than those of xPCNS@PVP/Mg in the same content. This was attributed to the increased grain sizes of the Mg particles after a high temperature of the PVP removal process.
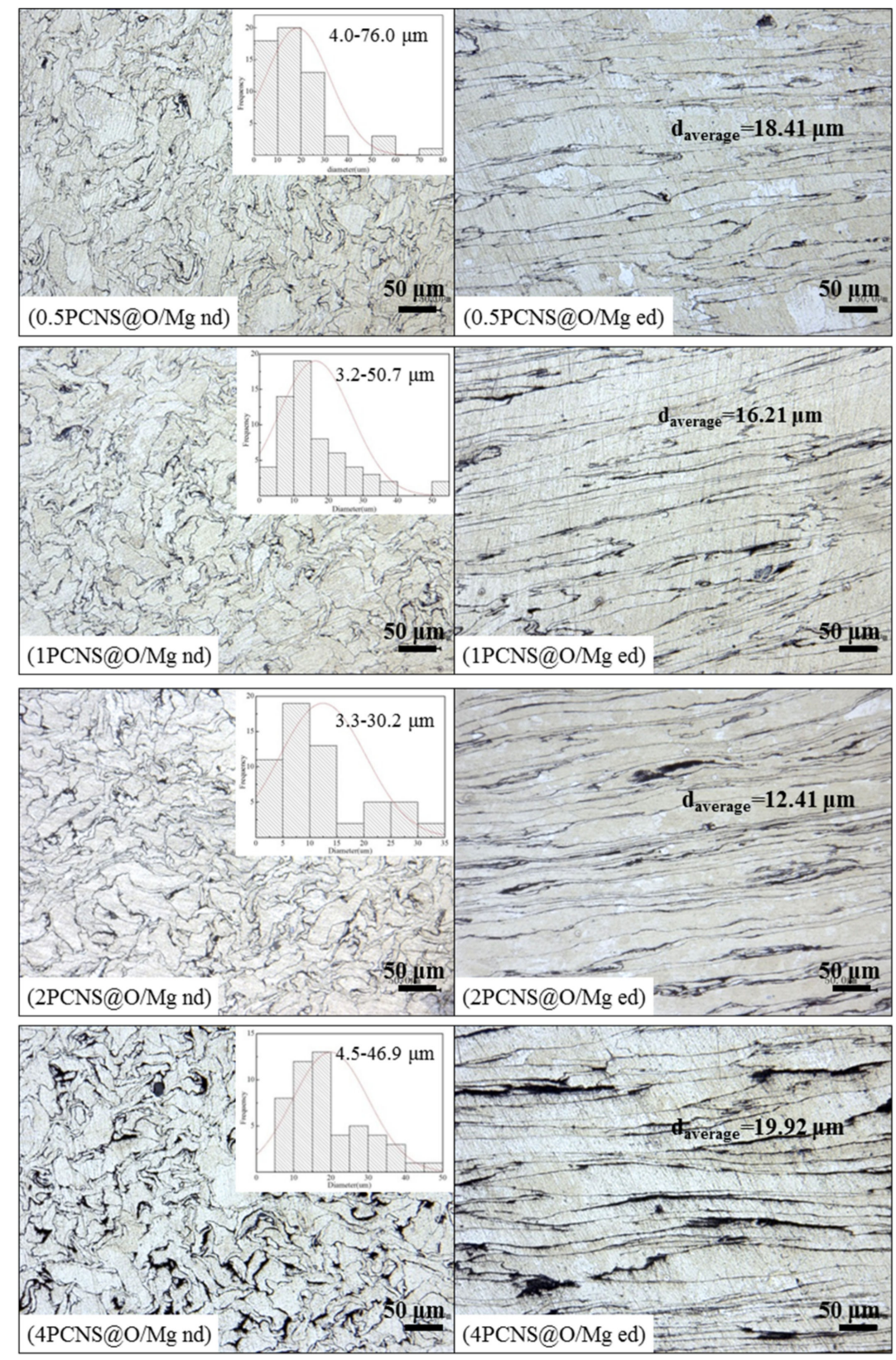

Figure 7. Optical micrographs of xPCNS@O/Mg bulk composites with the content of PCNS are 0.5, 1, 2 and 4 wt. $\%$.

In order to determine the positive impact of PVP in grain refinement, micrographs of $x \mathrm{PCNS} / \mathrm{Mg}$ composites without PVP were observed. It can be seen in Figure 8 that the average grain sizes of xPCNS/Mg decreased with increasing mass percentage of PCNS from 0.5 to 1 wt.\%, and many 
voids formed because of PCNS agglomeration. The average grain size of 1PCNS/Mg was $18.04 \mu \mathrm{m}$, larger than that of the composites prepared with PVP treatment. The volume of void increased with increasing content of PCNS; the width of the void section even reached $50 \mu \mathrm{m}$.
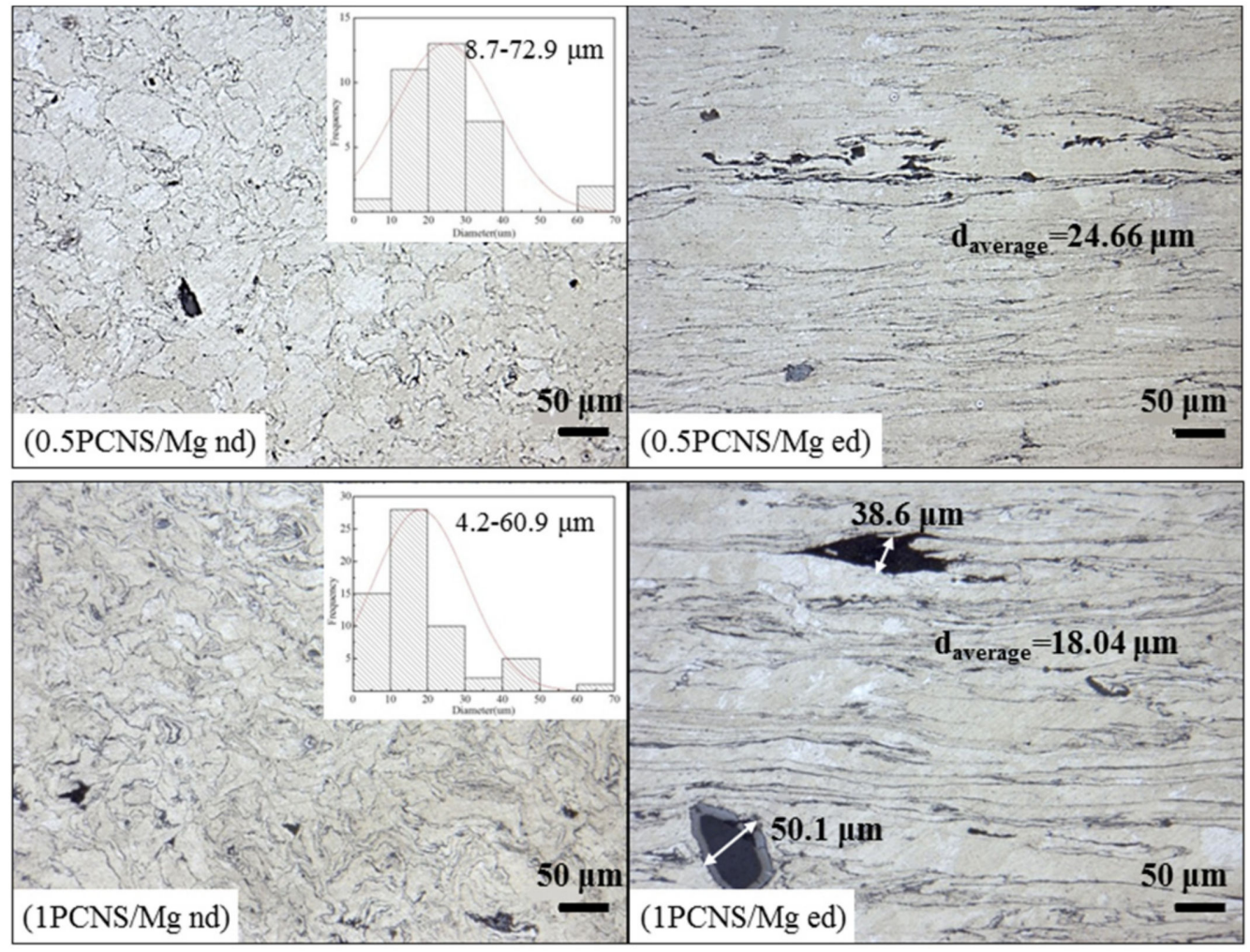

Figure 8. Optical micrographs of $x \mathrm{PCNS} / \mathrm{Mg}$ bulk composites with the content of PCNS is 0.5 and 1 wt.\%.

This illustrates the dispersity of PCNS is improved by PVP and still remains after the removal of the PVP. At the same time, the adding ratio of reinforcement can be increased by PVP treatment. All result proves PVP is effective in dispersing and binding PCNS in the Mg matrix. The dispersed PCNS can nail grain boundaries and hinder composite grain growth in the SPS process [21] and provides a valid nucleated particle for dynamic recrystallization in hot-pressing. The grains of composites are refined by hindering grain growth and dynamic recrystallization nucleation co-actions.

\subsection{Interfacial Microstructure}

The HRTEM and diffraction images at the interface of the 2PCNS@O/Mg sample are shown in Figure 9. There is a thick layer of about $6.2 \mathrm{~nm}$ at the interface between the PCNS and Mg matrix, as seen clearly in Figure 9a. The $d$-spacing value of this layer is measured as $0.214 \mathrm{~nm}$ corresponding to the (200) plane of the MgO. Combine with the EDS analysis of the sample (Figure 9c) and XRD pattern of PCNS@PVP/Mg and PCNS@O/Mg composite powders, confirms this layer is $\mathrm{MgO}$ film and produced in PVP removal. Furthermore, the planes with $d$-spacing values of $0.387 \mathrm{~nm}$ are exhibited in the interfacial region of $2 \mathrm{PCNS} @ \mathrm{O} / \mathrm{Mg}$, which are very close to $0.380 \mathrm{~nm}$. The studies present that the interface-binding of two phases is strongest when the distance between graphene and $\mathrm{MgO}$ is $0.380 \mathrm{~nm}$ in research $[22,23]$. The PCNS has many physical and chemical properties similar to graphene for its graphite-like structure. As a result, the interface-binding is strong between $\mathrm{MgO}$ and PCNS in 2PCNS@O/Mg composites. In addition, the PCNS prepared by the hydrothermal method have good interface-binding due to the oxygen functional groups on the surface of PCNS are effectively promoting the interface-binding of two phases [24]. 


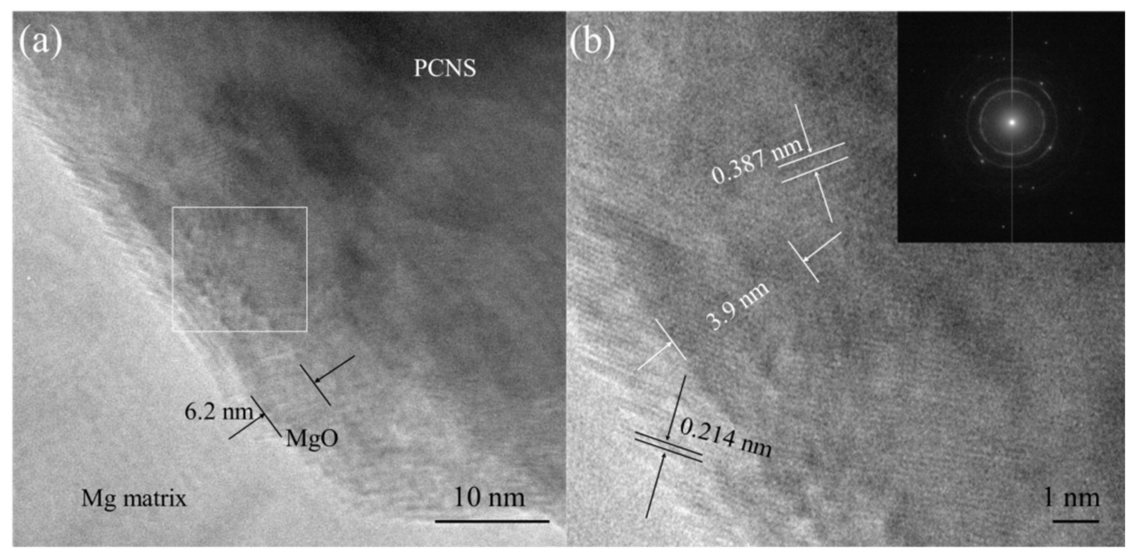

\begin{tabular}{|c|c|c|c|}
\hline (c) & Element & Weight $\%$ & Atomic $\%$ \\
\hline & $\mathrm{C}$ & 23.08 & 35.75 \\
\hline 6 & $\mathrm{O}$ & 13.51 & 15.71 \\
\hline & $\mathrm{Mg}$ & 63.42 & 48.54 \\
\hline
\end{tabular}

Figure 9. HRTEM image of (a) 2PCNS@O/Mg sample, (b) the enlarged image of the box in a and (c) the EDS results of the enlarged box $b$.

\subsection{Tensile Behavior}

There were three series of plate test specimens like "dog bone" with $30 \mathrm{~mm}$ length and $4 \mathrm{~mm}$ $\times 1.3 \mathrm{~mm}$ of initial cross-section area produced by xPCNS/Mg, xPCNS@PVP/Mg, xPCNS@O/Mg composites and pure Mg. The tensile testing of these specimens was applied in an AUTOGRAPH AGX-XD electronic universal testing machine under $20 \mathrm{kN}$ of tensile load and $0.6 \mathrm{~mm} / \mathrm{min}$ of the tensile rate at atmospheric temperature. Figure 10 shows the true tensile stress-strain curves of (a) xPCNS/Mg, (b) xPCNS@PVP/Mg, (c)xPCNS@O/Mg composites, and the value of the tensile yield, tensile ultimate strength and elongation of composite samples are shown in Table 3. The intensity of xPCNS@PVP/Mg and xPCNS@O/Mg composites are higher than that of xPCNS/Mg in the same mass percentage of reinforcement by analysis Figure 10 and Table 3, suggesting the PVP can disperse PCNS effectively, so that improve the properties of composites. The tensile yield and ultimate tensile strength of xPCNS@PVP/Mg and xPCNS@O/Mg composites first increase and then decrease with increasing content of PCNS from 0.5 to $4 \mathrm{wt} . \%$. The best tensile property is presented at $2 \mathrm{wt} . \%$ of PCNS in the Mg matrix of these composites. When the content of PCNS is up to $4 \mathrm{wt} . \%$, the tensile property of composite reduces because of the agglomeration of excessive PCNS, but larger than that of the $\mathrm{Mg}$ matrix. Both tensile yield (177 MPa) and ultimate tensile strength (206 MPa) of 2PCNS@O/Mg are the largest among these composites, increasing by $77 \%$ and $38 \%$ compared to that of pure $\mathrm{Mg}$, respectively. The tensile yield strengths of these composites are improved accordingly, but their elongations decline compared with the $\mathrm{Mg}$ matrix. Combine with XRD pattern and HRTEM image analysis; this is suggested the $\mathrm{MgO}$ films are produced in the interface between PCNS and Mg matrix by the oxidization of PCNS oxygen functional groups and PVP with Mg after PVP removal process, as seen, the oxidation-reduction equation: $\mathrm{Mg}+\mathrm{O} \rightarrow \mathrm{MgO}$. It is worth to know, $\mathrm{MgO}$ is a typical oxide ceramic belonging to the brittle phase, which has good tensile strength and poor ductility. Jerng et al. [25] found the interfacial bonding between carbon and $\mathrm{MgO}$ was stable. Therefore, $\mathrm{MgO}$ films produced in two phases can improve tensile yield and ultimate tensile strength of composites but reduce the elongation simultaneously. Furthermore, the in situ synthesis of the $\mathrm{MgO}$ on the matrix surface enhances the dispersity of reinforcement in the matrix [26]. 

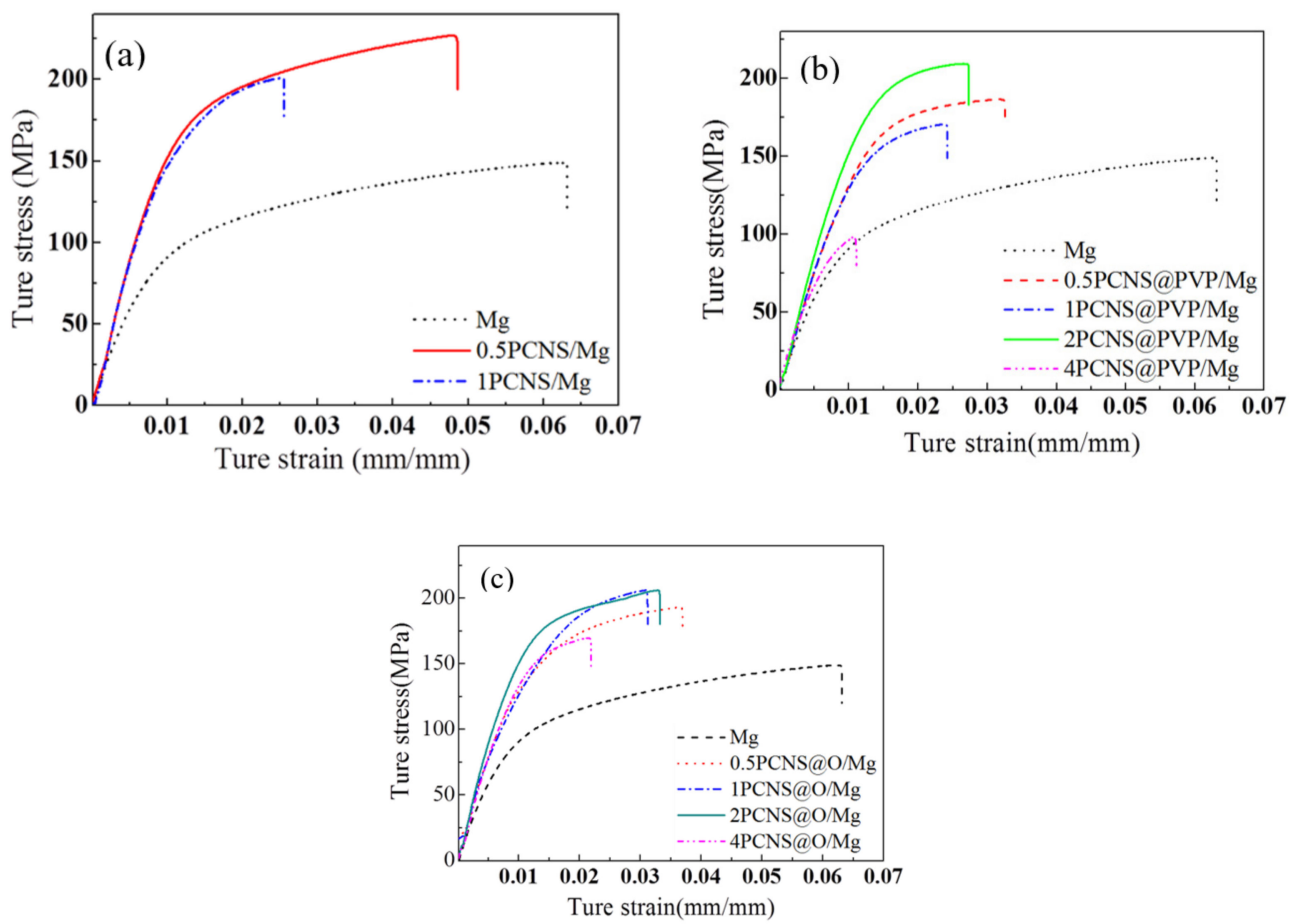

Figure 10. Tensile strength properties of (a) xPCNS/Mg, (b) xPCNS@PVP/Mg and (c) xPCNS@O/Mg composites.

The comparison of xPCNS@PVP/Mg and xPCNS@O/Mg composites shows xPCNS@O/Mg composites obtained by removing PVP have better tensile properties than xPCNS@PVP/Mg composites. For example, the tensile yield, tensile ultimate strength and elongation of composites were improved after removed PVP at high temperature, which suggests the removal of PVP in composites has a positive effect on the properties.

Table 3. Tensile yield and ultimate tensile strength of PCNS-reinforced Mg composites.

\begin{tabular}{ccccc}
\hline Sample & Mass Percentage of PCNS (wt.\%) & $\boldsymbol{\sigma 0 . 2} \mathbf{( M P a )}$ & $\boldsymbol{\sigma U T S}(\mathbf{M P a})$ & $\varepsilon(\%)$ \\
\hline $\mathrm{Mg}$ & 0 & 100 & 149 & 6.4 \\
0.5 PCNS/Mg & 0.5 & 140 & 227 & 4.8 \\
1 PCNS/Mg & 1 & 142 & 201 & 2.6 \\
0.5 PCNS@PVP/Mg & 0.5 & 150 & 186 & 3.2 \\
1 PCNS@PVP/Mg & 1 & 145 & 170 & 2.4 \\
2 PCNS@PVP/Mg & 2 & 165 & 209 & 2.7 \\
4 PCNS@PVP/Mg & 4 & 93 & 98 & 1.1 \\
0.5 PCNS@O/Mg & 0.5 & 148 & 193 & 3.7 \\
1 PCNS@O/Mg & 1 & 166 & 204 & 3.1 \\
2 PCNS@O/Mg & 2 & 177 & 206 & 3.4 \\
4 PCNS@O/Mg & 4 & 147 & 169 & 2.2 \\
\hline
\end{tabular}

The strength-to-weight ratio can be calculated according to the actual density and tensile yield strength of composites, are shown in Table 4. The strength-to-weight ratio of PCNS-reinforced Mg composites is obviously promoted with an increasing mass percentage of reinforcement because the density of PCNS is light, and the tensile strengths of composites are improved. The best strength-to-weight ratio presents at $2 \mathrm{wt} . \%$ of PCNS in the Mg matrix is $102.4 \times 10^{3} \mathrm{~N} \cdot \mathrm{m} / \mathrm{kg}$, with the increment of $78 \%$ larger than those of pure $\mathrm{Mg}$. It still has a degree of advantage even compared with $\mathrm{Al}$ and carbon nanotubes (CNTs) or SiC-reinforced Mg composites [27] for the density of PCNS is lighter than that of CNTs and SiC. 
Table 4. Strength-to weight ratio of PCNS-reinforced Mg composites.

\begin{tabular}{|c|c|c|c|}
\hline Sample & Tensile Yield Strength (MPa) & True Density $\left(\mathrm{g} / \mathrm{cm}^{3}\right)$ & Strength to-Weight Ratio $(\mathrm{N} \cdot \mathrm{m} / \mathrm{kg})$ \\
\hline $\mathrm{Mg}$ & 100 & 1.7362 & $57.6 \times 103$ \\
\hline 0.5 PCNS@O/Mg & 148 & 1.7381 & $85.2 \times 103$ \\
\hline 1 PCNS@O/Mg & 166 & 1.7319 & $95.8 \times 103$ \\
\hline 2 PCNS@O/Mg & 177 & 1.7282 & $102.4 \times 103$ \\
\hline 4 PCNS@O/Mg & 147 & 1.7101 & $86.0 \times 103$ \\
\hline Mg-1Al-0.3CNTs [27] & 166 & 1.7443 & $95.2 \times 103$ \\
\hline Mg-1Al-0.6CNTs [27] & 161 & 1.7400 & $92.5 \times 103$ \\
\hline $\mathrm{Mg}-1 \mathrm{Al}-0.6 \mathrm{SiC}[27]$ & 156 & 1.7557 & $88.8 \times 103$ \\
\hline Mg-1Al-1.2SiC [27] & 176 & 1.7646 & $99.7 \times 103$ \\
\hline $\mathrm{Mg}-1 \mathrm{Al}-2.4 \mathrm{SiC}$ [27] & 186 & 1.7679 & $95.0 \times 103$ \\
\hline
\end{tabular}

\section{Conclusions}

The PCNS can effectively enhance the properties of the Mg-base, and the PCNS-reinforced Mg composites were successfully prepared by PVP pretreatment, the PVP removal process, spark plasma sintered and hot-pressed method. When $\sim 2 \mathrm{wt} . \%$ of PCNS was added in the Mg matrix for preparing the composites, their tensile yield strength and specific strength exhibit $177 \mathrm{MPa}$ and $102.4 \times 103 \mathrm{~N} \cdot \mathrm{m} / \mathrm{kg}$, which are $77 \%$ and $78 \%$ higher than those of the Mg matrix, respectively. The simple PVP pretreatment is effective for enhancing the properties of the $\mathrm{Mg}$ matrix composites due to the uniform dispersion of PCNS reinforcements in the Mg matrix. Then the tensile yield and ultimate tensile strength of composites can be further improved because $\mathrm{MgO}$ films between the matrix and reinforcement promote their interface compatibility after the PVP removal process. The findings suggest that the PCNS can effectively enhance the properties of the $\mathrm{Mg}$ matrix. However, the poor ductility of the $\mathrm{MgO}$ films and the zero-dimensional structure of PCNS cause a decrease in the elongation of composites.

Author Contributions: Conceptualization, Y.-Z.Y. and J.-F.F.; methodology, L.J.; validation, Y.-Z.Y., J.-F.F. and B.-S.X.; formal analysis, L.J. and J.-F.F.; investigation, L.J.; resources, Y.-Z.Y. and J.-F.F.; data curation, L.J.; writing—original draft preparation, L.J.; writing—review and editing, Y.-Z.Y.; supervision, Y.-Z.Y. and J.-F.F.; project administration, J.-F.F. and B.-S.X. All authors have read and agreed to the published version of the manuscript.

Funding: This research was funded by the National Natural Science Foundation of China (U1810122 and 51601123), Outstanding Innovative Teams of Higher Learning Institutions of Shanxi (2018), the Natural Science Foundation of Shanxi Province (201801D221139).

Conflicts of Interest: The authors declare no conflict of interest.

\section{References}

1. Lan, J.; Yang, Y.; Li, X.-C. Microstructure and microhardness of SiC nanoparticles reinforced magnesium composites fabricated by ultrasonic method. Mater. Sci. Eng. A 2004, 386, 284-291. [CrossRef]

2. Cao, G.; Kobliska, J.; Konishi, H.; Li, X. Tensile properties and microstructure of SiC nanoparticle-reinforced $\mathrm{Mg}-4 \mathrm{Zn}$ alloy fabricated by ultrasonic cavitation-based solidification processing. Metall. Mater. Trans. A 2008, 39, 880-886. [CrossRef]

3. Cao, G.; Konishi, H.; Li, X. Mechanical properties and microstructure of SiC-reinforced Mg-(2,4)Al-1Si nanocomposites fabricated by ultrasonic cavitation based solidification processing. Mater. Sci. Eng. A 2008, 486, 357-362. [CrossRef]

4. Wang, Y.; Korai, Y.; Mochida, I. Carbon disc of high density and strength prepared from synthetic pitch-derived mesocarbon microbeads. Carbon 1999, 7, 1049-1057. [CrossRef]

5. Kim, Y.; Cho, C.; Kang, J.; Cho, Y.; Moon, J.-H. Synthesis of porous carbon balls from spherical colloidal crystal templates. Langmuir 2012, 28, 10543-10550. [CrossRef]

6. Titirici, M.; Antonietti, M. Chemistry and materials options of sustainable carbon materials made by hydrothermal carbonization. Chem. Soc. Rev. 2010, 39, 103-116. [CrossRef]

7. Peng, T.; Chang, I. Uniformly dispersion of carbon nanotube in aluminum powders by wet shake-mixing approach. Powder Technol 2015, 284, 32-39. [CrossRef] 
8. Gao, X.; Yue, H.-Y.; Guo, E.-J.; Zhang, H.; Lin, X.-Y.; Yao, L.H.; Wang, B. Preparation and tensile properties of homogeneously dispersed graphene reinforced aluminum matrix composites. Mater. Design 2016, 94, 54-60. [CrossRef]

9. Jiang, L.; Li, Z.-Q.; Fan, G.-L.; Cao, L.-L.; Zhang, D. Strong and ductile carbon nanotube/aluminum bulk nanolaminated composites with two-dimensional alignment of carbon nanotubes. Scr. Mater. 2012, 6, 331-334. [CrossRef]

10. Jiang, L.; Fan, G.-L.; Li, Z.-Q.; Kai, Z.-X.; Zhang, D.; Chen, Z.-X.; Humphries, S.; Heness, G.; Yeung, W.-Y. An approach to the uniform dispersion of a high volume fraction of carbon nanotubes in aluminum powder. Carbon 2011, 49, 1965-1971. [CrossRef]

11. Jiang, R.-R.; Zhou, X.-F.; Fang, Q.-L.; Liu, Z.-P. Copper-graphene bulk composites with homogeneous graphene dispersion and enhanced mechanical properties. Mater. Sci. Eng. A 2016, 654, 124-130. [CrossRef]

12. Jiang, C.-J.; Duan, Z.-W.; Zhang, Z.-Z.; Wang, C. Effect of surfactants on dispersing properties in alcohol solvent for silver nanopowders. Rare Met. Mater. Eng. 2007, 4, 724-727.

13. Nan, Q. Study on the Dispersion of Noncovalent Functionalization of Carbon Nanotubes in Solvents and Polymers. Master's Thesis, Taiyuan University of Technology, Taiyuan, China, 2017.

14. Wajid, A.-S.; Das, S.; Irin, F.; Ahmed, H.-S.; Shelburne, J.-L.; Parviz, D.; Fullerton, R.-J.; Jankowski, A.-F.; Hedden, R.-C.; Green, M.-J. Polymer-stabilized graphene dispersions at high concentrations in organic solvents for composite production. Carbon 2012, 50, 526-534. [CrossRef]

15. Jin, L.; Yang, Y.-Z.; Fan, J.-F.; Xu, B.-S. Improved dispersion of carbon microspheres reinforcement in $\mathrm{Mg}$ matrix composites. J. Taiyuan. Univ. Technol. 2020, 51, 363-371. [CrossRef]

16. Zhao, H.-J.; Yang, Y.-Z.; Liu, X.-G.; Xu, B.-S. Preparation of surface molecularly imprinted matrix materials porous carbon microspheres from glucose by hydrothermal carbonization method. China Sci. 2012, 7, 898-903.

17. Pandiyarajan, T.; Karthikeyan, B. Structural, thermal and optical properties of PVP capped ZnO films. Adv. Mater. Res. 2013, 678, 253-257. [CrossRef]

18. Jin, Y.-Z.; Gao, C.; Hsu, W.-K.; Zhu, Y.-Q.; Huczko, A.; Bystrzejewski, M.; Roe, M.; Lee, C.; Acquah, S.; Kroto, H.; et al. Large-scale synthesis and characterization of carbon spheres prepared by direct pyrolysis of hydrocarbons. Carbon 2005, 9, 1944-1953. [CrossRef]

19. Ma, A.-L.; Wang, X.-M.; Li, T.-B.; Liu, X.-G.; Xu, B.-S. Characteristics of carbon microspheres and study on its adsorption isotherms. Mater. Sci. Eng. 2007, 443, 54-59. [CrossRef]

20. Wang, X.-J.; Chen, D.-J.; Zhou, J.-J. Synthesis and characterization of the carbon nanotubes/magnesium oxide nanocomposite by precursor decomposing method. New Chem. Mater. 2009, 2, 35-37.

21. Chang, S.; Lee, S.; Kang, K.-M.; Kamado, S.; Kojima, Y. Improvement of mechanical characteristics in severely plastic-deformed Mg alloys. Mater. Trans. 2004, 45, 488-492. [CrossRef]

22. Ryou, J.; Hong, S. First-principles study of carbon atoms adsorbed on $\mathrm{MgO}(100)$ related to graphene growth. Curr. Appl. Phys. 2013, 13, 327-330. [CrossRef]

23. Yuan, Q.-H.; Zeng, X.-S.; Liu, Y.; Luo, L.; Wu, J.-B.; Wang, Y.-C.; Zhou, G.-H. Microstructure and mechanical properties of AZ91 alloy reinforced by carbon nanotubes coated with MgO. Carbon 2016, 96, 843-855. [CrossRef]

24. Jin, L.; Yang, Y.-Z.; Fan, J.-F.; Xu, B.-S. Effect of surface functionalization on properties of carbon microspheres reinforced magnesium composites. Mater. Rev. 2020, 8. accepted.

25. Jerng, S.; Lee, J.; Yu, D.; Kim, Y.; Ryou, J.; Hong, S.; Kim, C.; Yoon, S.; Chun, S. Graphitic carbon growth on $\mathrm{MgO}(100)$ by molecular beam epitaxy. J. Phys. Chem. C 2012, 116, 7380-7385. [CrossRef]

26. Kondoh, K.; Fukuda, H.; Umeda, J.; Imai, H.; Fugetsu, B.; Endo, M. Microstructural and mechanical analysis of carbon nanotube reinforced magnesium alloy powder composites. Mater. Sci. Eng. A 2010, 527, 4103-4108. [CrossRef]

27. Yan, Y. Mg Matrix Composites Reinforced with Nano Particles Fabricated by SPS Followed by Hot Extrusion. Master's Thesis, Taiyuan University of Technology, Taiyuan, China, 2017.

Publisher's Note: MDPI stays neutral with regard to jurisdictional claims in published maps and institutional affiliations. 